mucosa were not able to undergo respiratory burst. We suggest therefore that these cells which are unresponsive to interferon-gamma are 'desensitised' or downregulated. It is possible that the small proportion of macrophages from normal mucosa that are able to release oxygen radicals may enhance their production of these reactive metabolites after stimulation with interferon-gamma. However, this still leaves a large proportion that did not show evidence of being able to undergo respiratory burst after stimulation.

Our other studies have also shown that the macrophages from normal colonic mucosa are also not able to express interleukin- 2 receptors despite stimulation by interferon-gamma. In contrast, significant proportions of macrophages from mucosa with active inflammatory bowel disease expressed these receptors. ${ }^{2}$ That these latter cells are activated was shown by their capacity to release oxygen radicals. Macrophages isolated from mucosa with active inflammatory bowel disease also produce more interleukin-1ß (IL-1ß) than cells from norma mucosa. Lipopolysaccharide enhanced IL-1B production by cells from inflamed mucosa but not from normal mucosa. ${ }^{3}$ Our studies also suggest enhanced antigen presenting capacity by macrophages from mucosa with active inflammatory bowel disease.

We suggest, therefore, that a large proportion of macrophages in normal ileal and colonic mucosa are downregulated in their capacity to perform a number of functions. This downregulation may be required under normal physiological conditions to protect against injury. As we have reported, we suggest that the enhanced functions by macrophages from mucosa with active inflammatory bowel disease - for example, respiratory burst capacity and IL-1B production -are due in large part to the elicited population of cells (most likely circulating monocytes migrating into the mucosa) which are primed or in an enhanced state of activation. In the mucosa these cells may be phenotypically different. ${ }^{2}$

We do not think that prostaglandin $E_{2}$ is likely to be important in priming macrophages, as studies have shown that at very low concentrations it can inhibit class II expression. ${ }^{6}$ Enhanced class II expression is a feature of activated macrophages. ${ }^{8}$

Y R MAHIDA Department of Therapeutics, University Hospital, Queen's Medical Centre,
Nottingham NG7 2UH D P JEWELL Gastroenterology Unit, Radcliffe Infirmary Oxford

1 Mahida YR, Wu K, Jewell DP. Respiratory burs activity of intestinal macrophages in normal and inflamma

2 Mahida YR, Wu K, Patel S, Jewell DP. Interleukin 2 receptor expression by macrophages in inflam matory bowel disease. Clin Exp Immunol 1988 74: 382-6.

3 Mahida YR, Wu K, Jewell DP. Enhanced production of interleukin $1 B$ by mononuclear cells isolated from mucosa with active ulcerative colitis or Crohn's disease. Gut 1989; 30: 835-8.

4 Mahida YR, Wu K, Jewell DP. Characterisation of antigen presenting activity of mononuclear cells antigen presenting activity of mononuclear cells isolated from normal and inflammatory bowe
disease colon and ileum. Immunology 1988; 65: 543-9.

5 Mahida YR, Patel S, Gionchetti P, Vaux D, Jewell DP. Macrophage subpopulations in lamina propria of normal and inflamed colon and propria of normal and inflamed co

6 Synder DS, Beller DI, Unanue ER. Prostaglandins modulate macrophage Ia expression. Nature 1982; 299: 163-5.

7 Tripp CS, Wyche A, Unanue ER, Needleman P. The functional significance of the regulation of macrophage Ia expression by endogenous arachidonate metabolites in vitro. $\mathcal{F}$ Immuno 1986: 137: 3915-20.
8 Adams DO, Hamilton TA. The cell biology of macrophage activation. Ann Rev Immunol 1884; 2: 283-318.

\section{Intragastric acidity and serum gastrin after sufotidine}

SIR, - The recent paper by Smith and Pounder (Gut 1990; 31: 291-3) shows that the new competitive $\mathrm{H}_{2}$ receptor antagonist sufotidine, taken in doses of $600 \mathrm{mg}$ bd, induces virtually 24 hour gastric anacidity. Thus its antisecretory effect closely resembles that of the proton pump inhibitor omeprazole.'

The study, however, is not without relevant methodological problems.

(1) The gastric circadian acidity pattern is characterised by high frequency real pH fluctuations both in basal conditions and during drug induced events. These changes can be properly described using a scanning rate equal to or lower than one point per minute. ${ }^{2}$

The hourly sampling rate is inappropriate to represent what is happening to gastric acidity in time-dependent measurements ${ }^{34}$ and the usual acidity indexes calculated from these low frequency acquired $\mathrm{pH}$ profiles are almost invariably unreliable. ${ }^{4}$

(2) The trapezoidal rule is a fairly robust way of calculating integrals of functions that are not very smooth, provided that the increment is several times lower than the duration of the shortest fluctuation of the function to be integrated. ${ }^{5}$ Since the circadian $\mathrm{pH}$ profile shows many rapid real $\mathrm{pH}$ fluctuations ${ }^{2}$ the one hour step does not allow the use of this numerical integration method.

(3) The experimental data not included in their paper for 1000 and 2000 hours in duodenal ulcer patients, albeit in clinical remission, cannot be replaced with datapoints obtained in normal subjects. More important, acidity measurements pertaining to healthy subjects are unlikely to correspond to those achieved with a very powerful $\mathrm{H}_{2}$ receptor antagonist, such as sufotidine. Moreover, since the integral of equally spaced series of data reflects the arithmetic mean, this replacement is simply useless.

(4) The authors state that the significance of the difference between the integrated 24 hour values were assessed using Wilcoxon's matched pair signed rank test. Even in an ideal case in which all the after treatment values are lower or higher than the before treatment values, by definition a test of this type cannot provide a probability level lower than $2^{k}$, $k$ being the number of couples. ${ }^{6}$

With a sample size of $\mathrm{k}=7$, as that studied by Smith and Pounder, the minimum $p$ value one can obtain is $2^{-7}=1 / 128=0.008$. Therefore, the authors could not have found a probability level lower than $0 \cdot 001$. Moreover, since in one of the seven cases the gastrin integral did not increase, it is incorrect to report a p value of less than 0.001 .

$$
\begin{array}{r}
\text { G S MELA } \\
\text { E CAPUTO } \\
\text { G VILLA } \\
\text { Istituto Scientifico di Medicina } \\
\text { Interna, Cattedra di Clinica Medica } R \\
\text { V SAVARINO } \\
\text { P ZENTILIN } \\
\text { Cattedia di Gastroenterologia, } \\
\text { Genova, Italy }
\end{array}
$$

1 Fiorucci S, Santucci L, Farroni F, Pelli MA, Morelli A. Effect of omeprazole on gastroesophageal reflux in Barrett's esophagus. $A m \mathcal{F}$ Gastroenterol 1989; 84: 1263-7.

2 Mela GS, Savarino V, Moretti $\dot{M}$, Bonifacino G, Sumberaz A, Zentilin P. Clinical relevance of sampling rate in the characterization and anal- ysis of 24-hour gastric acidity. A report on 413 cases. Scand 7 Gastroenterol 1989; 24: 683-7.

3 Mela GS, Savarino V, Moretti M, Sumberaz A, Bonifacino $G$, Zentilin $P$. Influence of sampling rate in 24 hour gastric pH-metry analysis. Gastroenterol Clin Biol 1989; 13: 744-5.

4 Mela GS, Savarino V. Inaccuracy of hourly sampled $\mathrm{pH}$ measurements in describing the effect of antisecretory drugs on circadian gastric acidity. f Clin Pharmacol 1990; 30: 45-9.

5 Press WH, Flannery BP, Teukolwsy SA, Vettering WT. Numerical recipes. The art of scientific computing. Cambridge: Cambridge University computing. Cambridge:

6 Mood AM, Graybill FA, Boes DC. Introduction to the theory of statistics. New York: McGraw-Hill, the theory of stat

7 Armitage P, Berry G. Statistical methods in medical research. Oxford: Blackwell Scientific, 1987 526.

\section{Reply}

SIR, - We reject three out of four of Mela et al's criticisms.

(1) Twenty four hour intragastric acidity can be measured by either aspiration or the use of an intragastric probe. We have used the former method for the last 16 years, ' and it has certain advantages. It is extremely reproducible, ${ }^{2}$ and has produced reliable estimates of the effect of a range of antisecretory drug regimens. ${ }^{3}$ The use of a $\mathrm{pH}$ probe results in such an avalanche of data that Savarino and Mela have concluded that 'hourly $\mathrm{pH}$ values of continuous intraluminal monitoring and those of simultaneous gastric aspiration appeared to be better correlated if the elimination of noise disturbing the in vivo $\mathrm{pH}$-metry curves is obtained.'

(2) The use of the trapezoidal rule is another type of 'smoothing' - certainly the integration of observed values of either acidity or gastrin provides an easily understood measure of individual 24 hour responses.

(3) The samples for 1000 and 2000 hours were not aspirated, because they occurred immediately after a main meal and oral dosing with either sufotidine or placebo. We did not want to remove any active drug from the stomach. We know that intragastric acidity in either patients or healthy subjects is overwhelmed at these times by food buffer (see the similar value for 1400 hours in the same experiments). The substituted values tend to underestimate the antisecretory effect of sufotidine.

(4) The results of dosing with sufotidine $600 \mathrm{mg}$ bd are so clear that statistical analysis is almost superfluous, although we agree that the $\mathrm{p}$ values in Figures 2 and 4 are incorrect, and should be $<0.01$ and $<0.05$, respectively.

A wide range of techniques can be used for the mathematical and statistical analysis of 24 hour data. We believe that the advantages of our technique are that it is simple to perform and the mathematical presentation produces a clear result ${ }^{+}$- some statisticians tend to overinterpret 24 hour data.

$$
\begin{array}{r}
\text { J T L SMITH } \\
\text { R E POUNDER } \\
\text { Academic Department of Medicine, } \\
\text { Royal Free Hospital School of Medicine, } \\
\text { London NW3 } 2 P F
\end{array}
$$

1 Pounder RE, Williams JG, Milton-Thompson GJ Misiewicz JJ. Twenty-four hour control of intragastric acidity by cimetidine in duodenal intragastric acidity by cimetidine in du

2 Smith JTL, Nwokolo CU, Gavey C, Pounder RE. Tolerance during eight days of high-dose $\mathrm{H}$,-blockade: placebo-controlled studies of 24 hour acidity and gastrin. Aliment Pharmaco Therap 1990; 4S: 47-63.

3 Pounder RE, Lanzon-Miller S, Gavey CJ, Nwokolo CU, Prewett EJ, Sercombe J. The Royal Free Hospital protocol for 24-hour intragastric acidity and gastrin concentration. Dig Dis (in press). 